\title{
Dimensionality Changes in Crystalline Complexes Induced by Exposure to Air: Solid-State Studies Using Single Crystal and Powder X-ray Diffraction Methods
}

\author{
Antonia Neels*, Montserrat Alfonso ${ }^{\star}$, Déborah González Mantero, and Helen Stoeckli-Evans
}

\begin{abstract}
When they come into contact with air, coordination compounds can often change their appearance. For instance, the colour of the compound can change as transparent crystals become opaque microcrystalline solids. This visible transformation of the compound is frequently accompanied by structural modifications due to loss of solvent molecules or in the reverse case, the reaction with water from the air. Often, the dimensionality of the structures also varies and this aspect is demonstrated for three pairs of copper(II) complexes $(1 \mathrm{D} \rightarrow \mathrm{DD}, 1 \mathrm{D} \rightarrow 2 \mathrm{D}$ and $3 \mathrm{D} \rightarrow 2 \mathrm{D})$. The complementary use of single crystal and powder X-ray diffraction methods is indispensable for the evaluation of these structural changes.
\end{abstract}

Keywords: Coordination polymers $\cdot$ Solid-state transformations $\cdot \mathrm{X}$-ray powder diffraction

\section{Introduction}

For the study of the macroscopic behaviour of a given compound it is essential to know its three-dimensional structure and if it is stable in air or if decomposition, or transformation into another compound takes place. Chemical and physical analyses are often carried out on powdered samples in the presence of air. Under such conditions compounds can undergo structural transformations induced by the elimination of solvent molecules of crystallization, or in the reverse case, the reaction with moisture.

Transition metal complexes often contain coordinated solvent molecules and/or molecules of solvent of crystallization in the solid state. The three-dimensional struc-

\footnotetext{
${ }^{*}$ Correspondence: Dr. A. Neels

Institut de Chimie

Université de Neuchâtel

Av. de Bellevaux 51, CP2

CH-2007 Neuchâtel

Tel.: +413271838 85

Fax: +41327182511

E-Mail: antonia.neels@unine.ch

aPresent address:

R\&D UGC, MBT (Schweiz) Ltd

Vulkanstrasse 110

$\mathrm{CH}-8048$ Zürich
}

ture of such compounds can be obtained by using low-temperature single crystal X-ray analysis to avoid decomposition initiated by solvent loss. What happens to the structure of the coordination compound on drying, or in the reverse case, when the compound is hygroscopic and reacts with water from the air? Often the dimensionality of the structure is influenced, and this is demonstrated here for three pairs of copper(II) complexes, where various transformations, from $1 \mathrm{D} \rightarrow 0 \mathrm{D}, 1 \mathrm{D} \rightarrow 2 \mathrm{D}$ and $3 \mathrm{D}$ $\rightarrow 2 \mathrm{D}$, have been observed. These solidstate transformations were studied by the complementary use of single crystal and powder X-ray diffraction analysis. With the development in recent years of new detectors and X-ray sources, together with the appropriate software, three-dimensional structure analysis from X-ray powder diffraction data has experienced rapid progress [1].

\section{Results and Discussions}

\subsection{Transformation of a $1 D \mathrm{Cu}^{\prime \prime}$ Coordination Polymer into a Binuclear Complex}

The structure of the polymeric copper(II) complex $\left\{\left[\mathrm{Cu}_{2} \mathrm{Cl}_{4}(\right.\right.$ tampyz $\left.)\right]\left(\mathrm{H}_{2} \mathrm{O}\right)$ $2.25\}_{\mathrm{n}}(\mathbf{I a})$, where tampyz $=2,3,5,6$-tetra- kis(aminomethyl)pyrazine, was first solved by single crystal X-ray analysis [2]. A ladder-like one-dimensional polymer was found, with disordered water molecules of crystallization situated between the rungs of the ladder (Fig. 1a). The ligand coordinates in a bis-tridentate fashion and the copper atoms can be considered as having either a square planar geometry, or an elongated square bipyramidal geometry, where the axial $\mathrm{Cu}-\mathrm{Cl}$ bond lengths are 2.867(7) $\AA$ A. After some exposure to air the transparent blue crystals changed in appearance and became opaque and much paler in colour. The microcrystalline powder obtained was analyzed by X-ray powder diffraction. In addition to the diffraction pattern of the known compound Ia, a second phase was found. This was identified as the binuclear complex Ib (Fig. 1a) [4]. This is explained by a slow decomposition process involving the loss of the water molecules in compound Ia. The original octahedral coordination sphere of the copper atoms undergoes a transformation to that of a distorted square pyramidal geometry, with a $\tau$ value of 0.18 ( $\tau=0$ square pyramidal; $\tau=1$ trigonal bipyramidal [5]). The space group changes from Immm in Ia to Pnmn in Ib, which is related to a loss of symmetry in the molecule; $\mathrm{D}_{2 \mathrm{~h}}$ in Ia, but $\mathrm{C}_{2 \mathrm{v}}$ in Ib. The unit cell undergoes a remarkable shrinking of 
$25 \%$ along the $c$ axis, being $17.48 \AA$ for Ia and $13.08 \AA$ for Ib. Rietveld refinement was carried out on a single powder diffraction pattern for both compounds (Fig. 1b) [4].

\subsection{Transformation of a 1D-into a 2D Cull Coordination Polymer}

The one-dimensional coordination polymer $\left\{\left[\mathrm{Cu}_{2} \mathrm{Br}_{2}(\right.\right.$ bppzdc $\left.)\left(\mathrm{H}_{2} \mathrm{O}\right)_{3}\right]\left(\mathrm{CH}_{3} \mathrm{OH}\right)$ $\left.\left(\mathrm{H}_{2} \mathrm{O}\right)_{4}\right\}_{\mathrm{n}}$ (IIa), where bppzdc = methyl-5,6bis(2-pyridyl)pyrazine-2,3-dicarboyxylate, undergoes a transformation during the drying process. IIa was obtained by the reaction of bppzdc [6] with $\mathrm{CuBr}_{2}$ (1:2 ratio) in a methanol/water mixture. Transparent emerald green single crystals were obtained, which when left exposed to the air became opaque and pale green. One molecule of methanol and four water molecules, one of them being coordinated to a copper(II) ion, are lost. This results in a structural transformation giving rise to a twodimensional polymer $\left\{\left[\mathrm{Cu}_{2} \mathrm{Br}_{2}(\mathrm{bppzdc})\right.\right.$ $\left.\left.\left(\mathrm{H}_{2} \mathrm{O}\right)_{2}\right]\left(\mathrm{H}_{2} \mathrm{O}\right)\right\}_{\mathrm{n}}$ (IIb) (Fig. 2a). As the crystallinity of the solid was maintained, the structure of the dried complex IIb was solved using X-ray powder diffraction data. In complex IIa the monomer (Fig. 3), which is repeated in the chains, contains two structurally and chemically different copper(II) ions bridged by the bppzdc. The ligand coordinates in a tri-dentate fashion (via atoms $\mathrm{N} 1, \mathrm{~N} 3$ and $\mathrm{O} 1$ ) to $\mathrm{Cu} 1$ and in a mono-dentate fashion (via atom $\mathrm{O} 2$ ) to $\mathrm{Cu} 2$. Both copper ions have nearly perfect square pyramidal environments $\left(\tau_{\mathrm{Cu} 1}=\right.$ $\left.0.04 ; \tau_{\mathrm{Cu} 2}=0.06\right)$. The $\mathrm{Cu} 1$ coordination sphere is completed by two bromide anions, while three water molecules and one nitrogen atom from a pyridine ring of a neighbouring molecule complete the coordination sphere of $\mathrm{Cu} 2$. One carboxylate group of the ligand acts as a bridge between the monomer units resulting in the formation of a one-dimensional arrangement of molecules (Fig. 2a). Due to the Jahn-Teller distortion observed in copper(II) complexes the axial $\mathrm{Cu}-\mathrm{O}$ distances are significantly longer than the equatorial $\mathrm{Cu}-\mathrm{O}, \mathrm{N}$ distances. Complex IIa crystallises with one molecule of methanol and six water molecules per asymmetric unit, which gives rise to the formation of an extended hydrogen bonding network linking the chains.

During the drying process complex IIa transforms into complex IIb, losing the molecule of methanol and three water molecules per asymmetric unit (Fig. 2a). Interestingly, one of the three water molecules lost was coordinated to $\mathrm{Cu} 2$. Subsequently the free coordination site is taken by an oxygen atom of a carboxylate group from a neighbouring chain. This change in the assembly of the monomer units in the solid state was discovered by solving the structure of IIb from powder X-ray diffraction data. The unit cell undergoes a shrinking, especially the $b$-axis, which is significantly shorter in IIb, $30.3 \AA$, compared to $36.5 \AA$ in IIa. In addition, the space group changes from $\mathrm{P} 2 / 1$ for IIa to $\mathrm{P} 2 / \mathrm{n}$ for IIb. This is

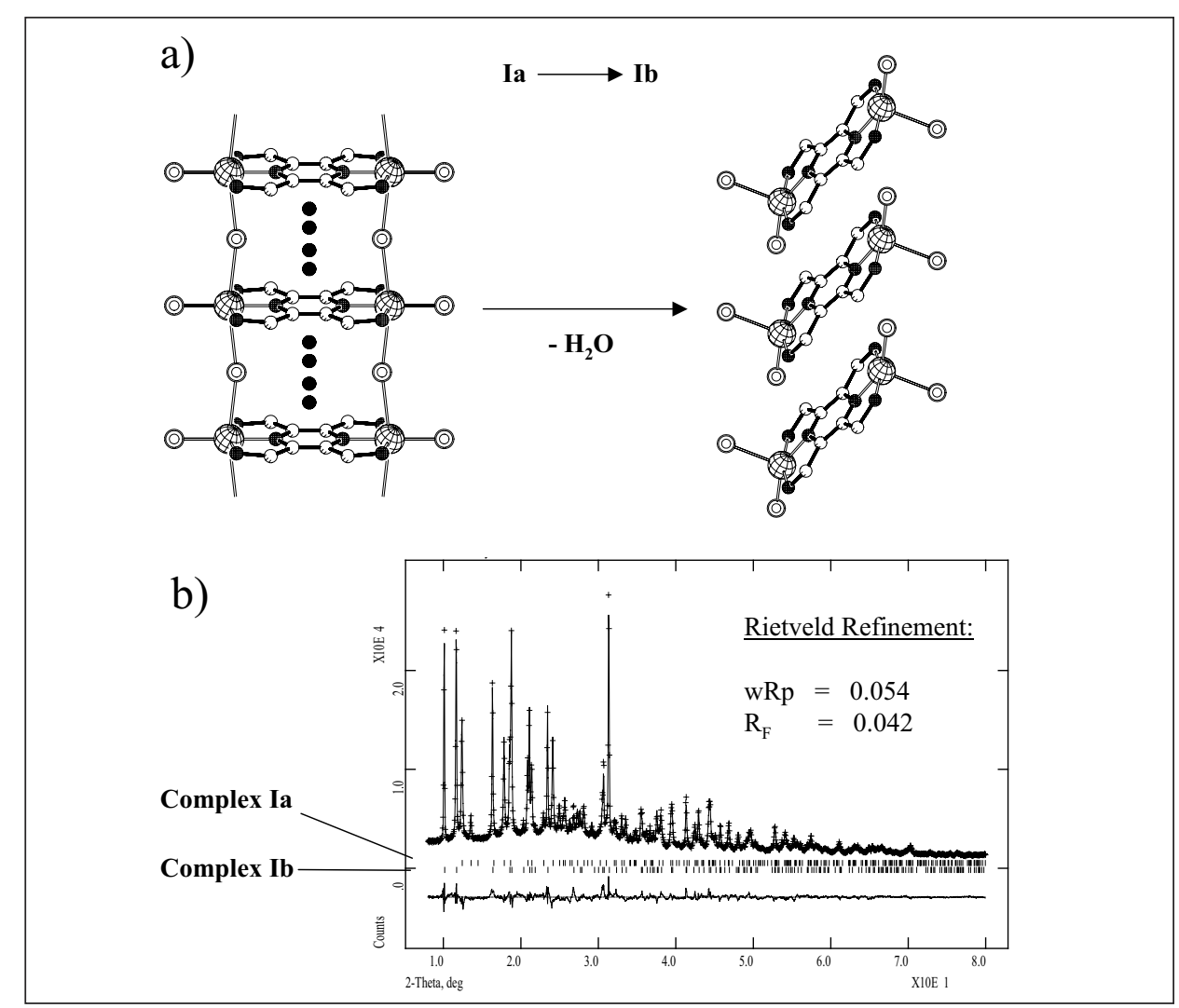

the result of a shift of $c a .4 .6 \AA$ in the direction of the $a$-axis of one chain against another. This is due to the loss of the solvent between the chains, and the simultaneous coordination of the carboxylate groups, as shown in Fig. 2a. The modified connection of molecules results in the formation of undulating double layers. For IIb, Rietveld refinement was carried out and good final agreement factors were obtained (Fig. 2b).

\subsection{Transformation of a 3D- into an Interpenetrating 2D Cull Coordination Polymer}

Coordination polymers with microporous channels are of interest due to their potential applications in gas adsorption, catalysis, molecular electronics, ceramics or ion exchange. Macroscopic studies on such polymers are based on the high stability of the microporous material. Consequently, the control of the three-dimensional structure is a fundamental aspect of this research. In the microporous coordination compound $\left\{\left[\mathrm{Cu}\left(4,4^{\prime}-\text {-bpy }\right)_{2}\left(\mathrm{~S}_{2} \mathrm{O}_{6}\right)\right]\left(\mathrm{H}_{2} \mathrm{O}\right)_{20}\right\}_{n}$ (IIIa), which was synthesized in the same manner as the known compound $\left\{\left[\mathrm{Cu}\left(4,4^{\prime}-\right.\right.\right.$ bpy $\left.\left.)_{2}\left(\mathrm{SiF}_{6}\right)\right]\left(\mathrm{H}_{2} \mathrm{O}\right)_{8}\right\}_{n}$ [8], copper(II) ions are linked by 4,4 '-bipyridine molecules and dithionate anions (Fig. 4a). This results in a three-dimensional framework containing channels, ca. $8 \times 8 \AA$, initially filled with water molecules. These channels are made up of square grids, $\mathrm{Cu}_{4}\left(4,4^{\prime} \text {-bpy }\right)_{4}$, pillared by dithionate anions leading to an interlayer spacing of $8.4 \AA$, compared to $8.0 \AA$ in the

Fig. 1. a) PLATON [3] drawing showing the transformation of $\mathbf{l a}$ into $\mathbf{l b}$, viewed down the $b$ axis (hydrogen atoms are omitted for clarity); b) Observed (+) and calculated (-) profiles of the Rietveld refinement for $\mathbf{l a}$ and $\mathbf{~} \mathbf{b}$. The bottom curve is the difference plot on the same intensity scale. 


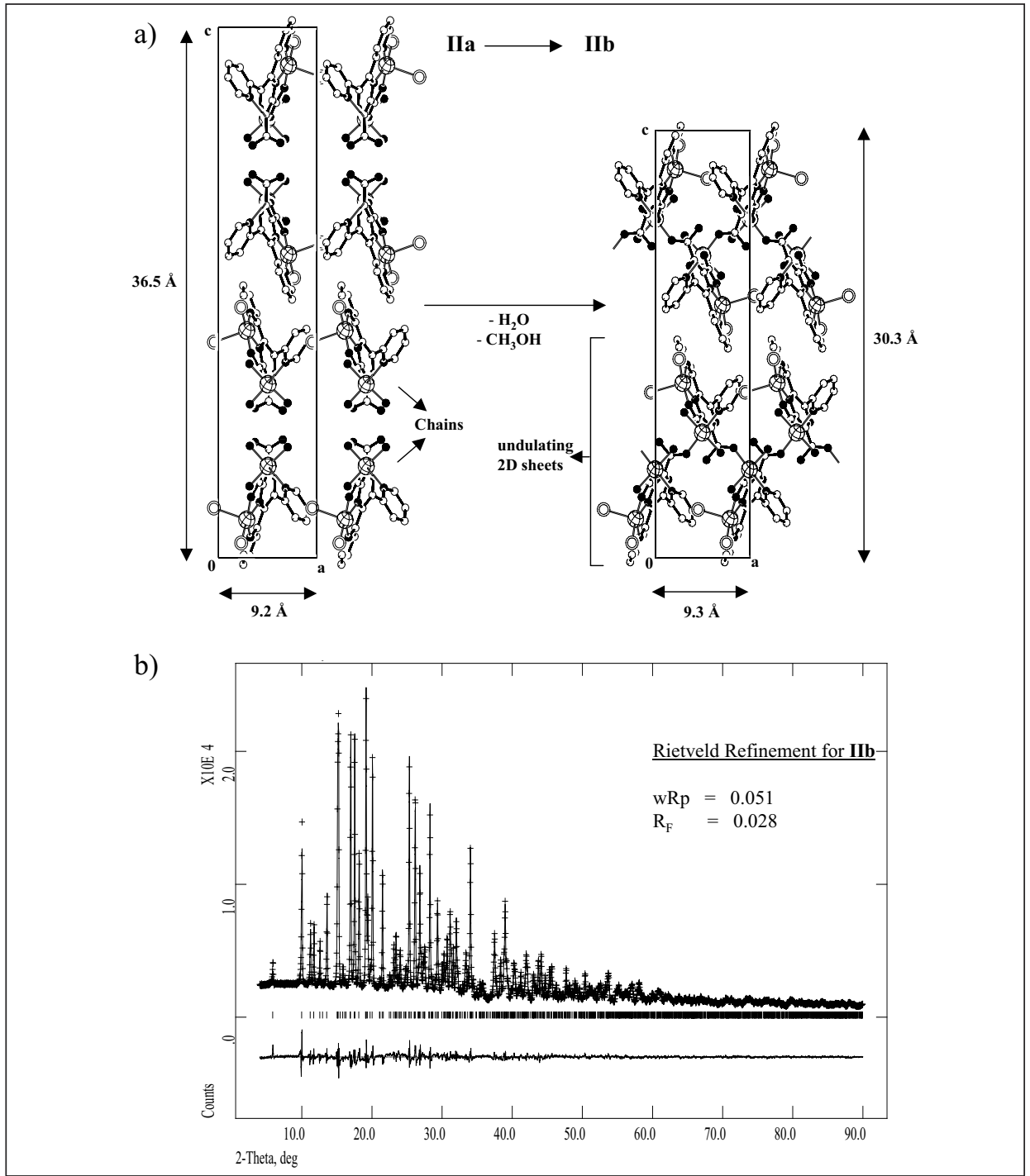

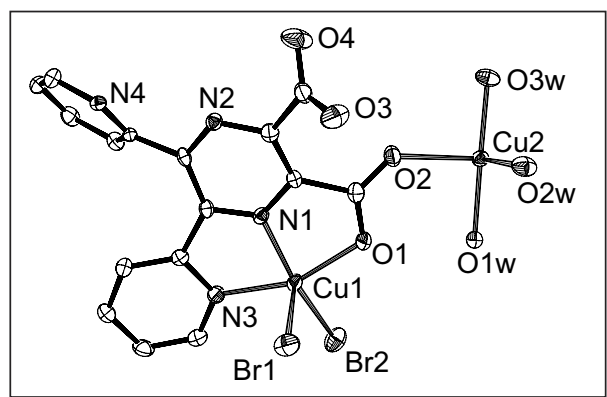

Fig. 3. ORTEP [7] drawing of the monomer unit of complex Ila, showing the numbering scheme (hydrogen atoms are omitted for clarity).

known compound $\left\{\left[\mathrm{Cu}\left(4,4^{\prime}-\text {-bpy }\right)_{2}\left(\mathrm{SiF}_{6}\right)\right]\right.$ $\left.\left(\mathrm{H}_{2} \mathrm{O}\right)_{8}\right\}_{\mathrm{n}}[8]$.

Removal of the water molecules in IIIa does not influence the stability of the compound, and the 3D framework is maintained on drying the crystals, as shown by the powder diffractograms (Fig. 4c). However, when exposed to air, i.e. humidity, the dithionate anions migrate into the cavities of the structure so liberating two copper coordination sites for water molecules. This results in the formation of an interpenetrat-
Fig. 2. a) Transformation of complex Ila into Ilb, viewed down the $b$ axis (hydrogen atoms are omitted for clarity); b) Observed (+) and calculated (-) profiles of the Rietveld refinement for Ilb. The bottom curve is the difference plot on the same intensity scale. ing 2D network, IIIb (Fig. 4b). During the solid-state transformation, the initial dark purple powder changes colour to sky blue, and the corresponding structural changes can be followed by X-ray powder diffraction studies (Fig. 4c). Analogous observations have been shown for the known compound $\quad\left\{\left[\mathrm{Cu}\left(4,4^{\prime}-\mathrm{bpy}_{2}\right)_{2}\left(\mathrm{SiF}_{6}\right)\right]\left(\mathrm{H}_{2} \mathrm{O}\right)_{8}\right\}_{\mathrm{n}}$ [9][10]. Compound IIIb was also obtained in the form of sky blue block-like crystals as a side product during the synthesis of IIIa. Structure analyses for both complexes have been carried out using single crystals, while the transformation in the solid phase was proven using powder diffraction methods. After an initial measurement of a powder sample of IIIa, the same capillary was exposed to air and measured at intervals. The colour of the powder changed from purple to blue and diffraction peaks for both IIIa and IIIb were observed; the percentage of the latter increasing with time.

\section{Conclusions}

Single crystal X-ray analysis is an essential analytical tool in chemistry today especially in the field of coordination chemistry. With the development of new materials, which often do not form single crystals, structure analysis using powder diffraction X-ray data is becoming a useful technique to characterize such materials. Simple exposure to air of single crystals and certain dried solids can lead to important structural transformations, which must be understood in order to explain any changes in physical and/or chemical properties.

\section{Supplementary data}

Crystallographic data (including experimental and refinement details, but excluding structure factors) for all six structures are deposited with the Cambridge Crystallographic Data Centre as supplementary publication nos. CCDC 103029 (Ia-powder), CCDC Refcode PITXIZ (Ia-single 


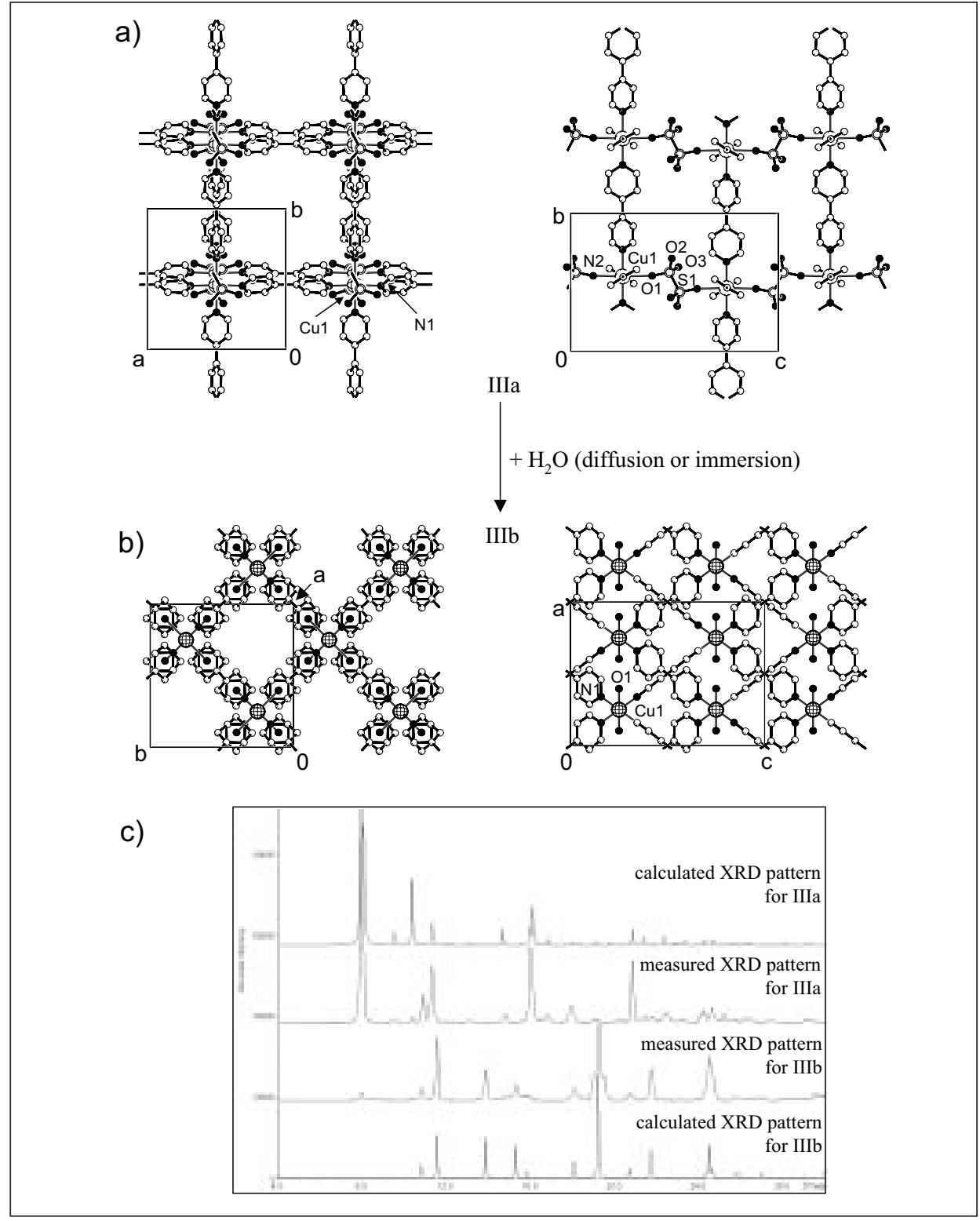

crystal), CCDC 103030 (Ib-powder), CCDC 210805 (IIa-single crystal), CCDC 210806 (IIb-powder), CCDC 210807 (IIIa-single crystal) \& CCDC 210808 (IIIb-single crystal). Copies of the data can be obtained free of charge on application to Cambridge Crystallographic Data Centre, 12 Union Road, Cambridge CB2 1EZ, UK [Fax: (internat.) +44-1223/336033; E-Mail: deposit@ccds.cam.ac.uk].

\section{Acknowledgements}

Financial support from the Swiss National Science Foundation is gratefully acknowledged.

Received: July 14, 2003

[1] The following book gives an excellent upto-date review of the field: 'Structure Determination from Powder Diffraction Data', Eds. W.I.F. David, K. Shankland, L.B. McCusker, C. Baerlocher, IUCr Monograph on Crystallography No. 13, Oxford
Science Publications, Oxford University Press, Oxford, UK, 2002.

[2] M. Ferigo, P. Bonhôte, W. Marty, H. Stoeckli-Evans, J. Chem. Soc. Dalton Trans. 1994, 1549-1554.

[3] A. Spek, "PLATON V-280602", Acta Crystallogr. 1990, A46, C-34.

[4] A. Neels, H. Stoeckli-Evans, Anales de Chimica Int. Ed. 1998, 94, 363-368.

[5] A.W. Addison, T.N. Rao, J. Reejik, J. van Rijn, G.C. Verschoor, J. Chem. Soc. Dalton Trans. 1984, 1349-1356.

[6] M. Alfonso, Y. Wang, H. Stoeckli-Evans, Acta Crystallogr. 2001, C57, 1184.

[7] K. Johnson, ORTEP, Report ORNL-3794, Oak Ridge National Laboratory, Oak Ridge, TN, USA, 1976.

[8] S. Noro, S. Kitagawa, M. Kondo, K. Seki, Angew. Chem. Int. Ed. 2000, 39, 2082.

[9] S. Noro, R. Kitaura, M. Kondo, S. Kitagawa, T. Ishii, H. Matsuzaka, M. Yamashita, J. Am. Chem. Soc. 2002, 124, 2568.

[10] A. Neels, H. Stoeckli-Evans, Poster, XIX IUCr Congress and General Assembly, Geneva, 2002
Fig. 4. a) 3D polymer Illa with the numbering scheme (hydrogen atoms are omitted for clarity); b) 2D interpenetrating network of IIIb with the numbering scheme (the strongly disordered $\mathrm{S}_{2} \mathrm{O}_{6}{ }^{2-}$ anions are omitted for clarity); c) calculated and measured X-ray powder diffraction patterns for IIla and IIIb. 